\title{
Performance Improvement of Classifiers Utilizing Integration of Clustering and Analysis Techniques
}

\author{
P.Nandhini, R. Velvizhi, Shanmugapriya.
}

\begin{abstract}
Medical experts require a solid forecast philosophy to analyze Diabetes. Information mining is the way toward breaking down information from alternate points of view and outlining it into valuable data. The primary objective of information mining is to find new examples for the clients and to translate the information examples to give significant and valuable data to the clients. Information mining is connected to discover valuable examples to help in the essential errands of therapeutic determination and treatment. In this paper, execution examination of straightforward grouping calculations and incorporated bunching and arrangement calculations are done. It was discovered that the incorporated bunching characterization method was superior to the basic grouping strategy. Information mining device utilized is WEKA. PIMA INDIANS DIABETES dataset is utilized.
\end{abstract}

Keywords : BayesNet, NavieBayes, OneR.

\section{INTRODUCTION}

Data mining is the procedure of programmed order of cases in view of information designs acquired from a dataset. Various calculations have been created and actualized to remove data and find learning designs. Information Mining, additionally prominently known as Knowledge Discovery in Databases (KDD). The KDD strategy is connected on huge measure of information from put away database/information distribution center/any information archive for removing designs, connections, changes, oddities and covered up or center data utilizing calculations and systems.

Grouping is an essential undertaking in the information investigation that requires the development of a classifier, that is, a capacity that relegates a class mark to examples depicted by an arrangement of properties. It is one of the vital uses of information mining. This method predicts all out class marks. It is an administered learning strategy. Order of information is exceptionally run of the mill undertaking in information mining. The objective of arrangement is to accurately foresee the esteem. Grouping Algorithms utilized are NavieBayes, BayesNet, OneR and J48. [1-10]

Revised Manuscript Received on July 22, 2019

P.Nandhini, Dapartment of Computer Science and Engineering „Bharath Insitute of Higher Education and Research,,Chennai,India.

R. Velvizhi, Dapartment of Computer Science and Engineering „Bharath Insitute of Higher Education and Research,, Chennai, India. velvizhisp@gmail.com

Shanmugapriya, Dapartment of Computer Science and Engineering, Bharath Insitute of Higher Education and Research,,Chennai,India.

\section{PROPOSED METHOD}

Order is the procedure which finds the basic properties among an arrangement of articles in a database and characterizes them into various classes, as indicated by a grouping model. Bunching is the undertaking of fragmenting a various gathering into various comparative subgroups or groups. In this proposed strategy first the grouping calculation is connected on the dataset with the assistance of any bunching calculations, for example, Simple K-Means and Density Based Clustering. Grouping calculation includes the quality "bunch on the dataset. From that point forward, order calculation is connected on this bunched dataset. This approach gives comes about with a superior precision than the straightforward grouping strategy. [11-15]

A.Dataset:

Weak utilizes informational index (Attribute-relationship) document of ".arff" design. This informational index comprises of characteristic names, sorts, values and the information. In this paper, "Diabetes Diagnosis" is utilized. Informational index contains eight properties, one class property and 768 examples.[16-20]

B.Clustering:

Bunching is an unsupervised technique for information mining. In grouping client needs to characterize their own classes as indicated by class factors, here no predefined classes are available. In weka number of bunching calculations are available like spider web, DBSCAN, FarthestFirst, SimpleK-Means and so on.

Straightforward K-Means calculation:

The essential advance of k-implies grouping is basic. In the first place, we decide number of group $\mathrm{K}$ and we expect the centroid or focal point of these bunches. We can take any arbitrary protests as the underlying centroids or the main $\mathrm{K}$ items can likewise fill in as the underlying centroids. At that point the $\mathrm{K}$ implies calculation will do the four stages underneath until merging [20-25]

Thickness Based Clustering:

Thickness based bunching calculations attempt to discover groups in light of thickness of information focuses in a district. The key thought of thickness based grouping is that for each occasion of a bunch the area of a given range (Eps) needs to contain atleast a base number of examples (MinPts). To discover a group, it begins with a self-assertive occurrence (p) in informational index (D) and recovers all examples of D concerning Eps and Min Pts.

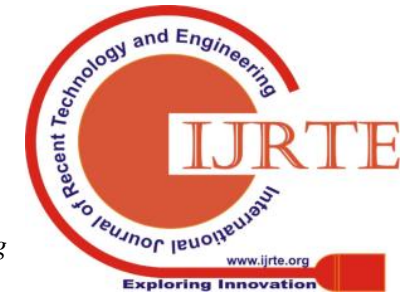


The calculation influences utilization of a spatial information to structure to find focuses inside Eps separate from the center purposes of the groups. Calculation is given underneath.

1) Start with a subjective beginning stage that has not been gone by.

2) Extract the area of this point utilizing $\varepsilon$ (All focuses which are inside the $\varepsilon$ separate are neighborhood).

3 ) If there is adequate neighborhood around this point at that point grouping process begins and point is set apart as went to else this point is marked as clamor (Later this point can turn into the piece of the bunch).

4) If a point is observed to be a piece of the group then its $\varepsilon$ neighborhood is likewise the piece of the bunch and the above system from stage 2 is rehashed for all $\varepsilon$ neighborhood focuses. This is rehashed until the point that all focuses in the bunch are resolved. [41]

5) A new unvisited point is recovered and handled, prompting the revelation of a further group or clamor.

6) This process proceeds until the point that all focuses are set apart as went to.[26-28]

\section{CLASSIFICATION}

Information order is an essential undertaking in information mining. For ordering an information mining issue, quantities of characterization calculations are utilized like Bayes, Functions, misc, Rules, Trees and so on. The point of characterization is to figure the estimations of every factor and dole out those factors to coordinated predefined classes. In this paper, four diverse grouping calculations have been utilized, which have been recorded underneath:

NaïveBayes (NB): A free component likelihood demonstrate, it depends on the Bayes hypothesis and is along these lines a probabilistic classifier.

BayesNet(BN) : By utilizing the bayes hypothesis BayesNet can be produced. To structure a Baysian organize first restrictive likelihood of each hub must be computed. Non-cyclic diagrams are utilized to speak to the system.

OneR : OneR, another way to say "One Rule", is a straightforward, precise, grouping calculation that creates one manage for every indicator in the information, at that point chooses the run with the littlest aggregate blunder as its "one run the show". [29]

J48: It is an upgraded form of $\mathrm{C} 4.5$ calculation. At the point when a particular information thing is ordered, it will be separated in various levels beginning from root hub to the leaf or terminal hub in a progressive way. [30-35]

\section{TEST RESULTS}

The examinations performed on the dataset gave the outcomes as demonstrated as follows. This table demonstrates the exactness measure of the straightforward grouping calculations, coordination of bunching and characterization utilizing Simple K-Means and combination of bunching and arrangement utilizing Density Based Clustering Algorithm. From the table, obviously the execution of classifiers has been enhanced subsequent to bunching. [36-40]

\section{CONCLUSION AND FUTURE WORK}

In this paper four distinct classifiers are coordinated with the basic k-implies grouping calculation and thickness based bunching calculation. This coordination system was connected on "Diabetes" informational index. From the perception and examination it was reasoned that the execution of Density Based + NavieBayes is superior to different calculations as a result of the accompanying highlights:

1. Number of effectively characterized occurrences is more

2. Absolute mistakes are less.

There are vast quantities of classifiers present and numerous other information mining devices are available. So the future work will be founded on different classifiers that can be connected on the informational index and furthermore to apply other information mining devices on the informational index with the end goal that as well as can be expected be distinguished. Above calculations can be connected to different datasets so as to watch whether a similar calculation gives the most elevated precision.

Bunching is an information mining method to aggregate the comparative information.

\section{REFERENCES}

[1] Kumarave A., Rangarajan K.,Algorithm for automaton specification for exploring dynamic labyrinths,Indian Journal of Science and Technology,V-6,I-SUPPL5,PP-4554-4559,Y-2013

[2] P. Kavitha, S. Prabakaran "A Novel Hybrid Segmentation Method with Particle Swarm Optimization and Fuzzy C-Mean Based On Partitioning the Image for Detecting Lung Cancer" International Journal of Engineering and Advanced Technology (IJEAT) ISSN: 2249-8958, Volume-8 Issue-5, June 2019

[3] Kumaravel A., Meetei O.N.,An application of non-uniform cellular automata for efficient cryptography,2013 IEEE Conference on Information and Communication Technologies, ICT 2013,V-,I-,PP-1200-1205,Y-2013

[4] Kumarave A., Rangarajan K.,Routing alogrithm over semi-regular tessellations,2013 IEEE Conference on Information and Communication Technologies, ICT 2013,V-,I-,PP-1180-1184,Y-2013

[5] P. Kavitha, S. Prabakaran "Designing a Feature Vector for Statistical Texture Analysis of Brain Tumor" International Journal of Engineering and Advanced Technology (IJEAT) ISSN: 2249-8958, Volume-8 Issue-5, June 2019

[6] Dutta P., Kumaravel A.,A novel approach to trust based identification of leaders in social networks, Indian Journal of Science and Technology,V-9,I-10,PP--,Y-2016

[7] Kumaravel A., Dutta P.,Application of Pca for context selection for collaborative filtering,Middle - East Journal of Scientific Research,V-20,I-1,PP-88-93,Y-2014

[8] Kumaravel A., Rangarajan K.,Constructing an automaton for exploring dynamic labyrinths,2012 International Conference on Radar, Communication and Computing, ICRCC 2012,V-,I-,PP-161-165,Y-2012

[9] P. Kavitha, S. Prabakaran "Adaptive Bilateral Filter for Multi-Resolution in Brain Tumor Recognition" International Journal of Innovative Technology and Exploring Engineering (IJITEE) ISSN: 2278-3075, Volume-8 Issue-8 June, 2019

[10] Kumaravel A.,Comparison of two multi-classification approaches for detecting network attacks, World Applied Sciences Journal,V-27,I-11,PP-1461-1465,Y-2013

[11] Tariq J., Kumaravel A.,Construction of cellular automata over hexagonal and triangular tessellations for path planning of multi-robots,2016 IEEE International Conference on Computational Intelligence and Computing Research, ICCIC 2016,V-,I-,PP--,Y-2017

[12] Sudha M., Kumaravel A.,Analysis and measurement of wave guides using poisson method,Indonesian Journal of Electrical Engineering and Computer Science,V-8,I-2,PP-546-548,Y-2017

[13] Ayyappan G., Nalini C., Kumaravel A.,Various approaches of knowledge transfer in academic social network,International Journal of Engineering and Technology,V-,I-,PP-2791-2794,Y-2017




[14] Kaliyamurthie, K.P., Sivaraman, K., Ramesh, S. Imposing patient data privacy in wireless medical sensor networks through homomorphic cryptosystems 2016, Journal of Chemical and Pharmaceutical Sciences 92.

[15] Kaliyamurthie, K.P., Balasubramanian, P.C.An approach to multi secure to historical malformed documents using integer ripple transfiguration 2016 Journal of Chemical and Pharmaceutical Sciences 92

[16] A.Sangeetha,C.Nalini,"Semantic Ranking based on keywords extractions in the web", International Journal of Engineering \& Technology, 7 (2.6) (2018) 290-292

[17] S.V.GayathiriDevi,C.Nalini,N.Kumar,"An efficient software verification using multi-layered software verification tool "International Journal of Engineering \& Technology, 7(2.21)2018 454-457

[18] C.Nalini,ShwtambariKharabe,"A Comparative Study On Different Techniques Used For Finger - Vein Authentication", International Journal Of Pure And Applied Mathematics, Volume 116 No. 8 2017, 327-333, Issn: 1314-3395

[19] M.S. Vivekanandan and Dr. C. Rajabhushanam, "Enabling Privacy Protection and Content Assurance in Geo-Social Networks", International Journal of Innovative Research in Management, Engineering and Technology, Vol 3, Issue 4, pp. 49-55, April 2018.

[20] Dr. C. Rajabhushanam, V. Karthik, and G. Vivek, "Elasticity in Cloud Computing", International Journal of Innovative Research in Management, Engineering and Technology, Vol 3, Issue 4, pp. 104-111, April 2018.

[21] K. Rangaswamy and Dr. C. Rajabhushanamc, "CCN-Based Congestion Control Mechanism In Dynamic Networks", International Journal of Innovative Research in Management, Engineering and Technology, Vol 3, Issue 4, pp. 117-119, April 2018.

[22] Kavitha, R., Nedunchelian, R., "Domain-specific Search engine optimization using healthcare ontology and a neural network backpropagation approach", 2017, Research Journal of Biotechnology, Special Issue 2:157-166

[23] Kavitha, G., Kavitha, R., "An analysis to improve throughput of high-power hubs in mobile ad hoc network" , 2016, Journal of Chemical and Pharmaceutical Sciences, Vol-9, Issue-2: 361-363

[24] Kavitha, G., Kavitha, R., "Dipping interference to supplement throughput in MANET", 2016, Journal of Chemical and Pharmaceutical Sciences, Vol-9, Issue-2: 357-360

[25] Michael, G., Chandrasekar, A.,'Leader election based malicious detection and response system in MANET using mechanism design approach", Journal of Chemical and Pharmaceutical Sciences(JCPS) Volume 9 Issue 2, April - June 2016.

[26] Michael, G., Chandrasekar, A.,'Modeling of detection of camouflaging worm using epidemic dynamic model and power spectral density", Journal of Chemical and Pharmaceutical Sciences(JCPS) Volume 9 Issue 2, April - June 2016.

[27] Pothumani, S., Sriram, M., Sridhar, J., Arul Selvan, G., Secure mobile agents communication on intranet,Journal of Chemical and Pharmaceutical Sciences, volume 9, Issue 3, Pg No S32-S35, 2016

[28] Pothumani, S., Sriram, M., Sridhar, Various schemes for database encryption-a survey, Journal of Chemical and Pharmaceutical Sciences, volume 9, Issue 3, Pg NoS103-S106, 2016

[29] Pothumani, S., Sriram, M., Sridhar, A novel economic framework for cloud and grid computing, Journal of Chemical and Pharmaceutical Sciences, volume 9, Issue 3, Pg No S29-S31, 2016

[30] Priya, N., Sridhar, J., Sriram, M. "Ecommerce Transaction Security Challenges and Prevention Methods- New Approach” 2016 ,Journal of Chemical and Pharmaceutical Sciences, JCPS Volume 9 Issue 3.page no:S66-S68 .

[31] Priya, N.,Sridhar,J.,Sriram, M."Vehicular cloud computing security issues and solutions" Journal of Chemical and Pharmaceutical Sciences(JCPS) Volume 9 Issue 2, April - June 2016

[32] Priya, N., Sridhar, J., Sriram, M. "Mobile large data storage security in cloud computing environment-a new approach" JCPS Volume 9 Issue 2. April - June 2016

[33] Anuradha.C, Khanna.V, "Improving network performance and security in WSN using decentralized hypothesis testing "Journal of Chemical and Pharmaceutical Sciences(JCPS) Volume 9 Issue 2, April - June 2016 .

[34] Anuradha.C, Khanna.V, "A novel gsm based control for e-devices" Journal of Chemical and Pharmaceutical Sciences(JCPS) Volume 9 Issue 2, April - June 2016 .

[35] Anuradha.C, Khanna.V, "Secured privacy preserving sharing and data integration in mobile web environments " Journal of Chemical and Pharmaceutical Sciences(JCPS) Volume 9 Issue 2, April - June 2016.
[36] Sundarraj, B., Kaliyamurthie, K.P. Social network analysis for decisive the ultimate classification from the ensemble to boost accuracy rates 2016 International Journal of Pharmacy and Technology 8

[37] Sundarraj, B., Kaliyamurthie, K.P. A content-based spam filtering approach victimisation artificial neural networks 2016 International Journal of Pharmacy and Technology $8 \quad 3$.

[38] Sundarraj, B., Kaliyamurthie, K.P. Remote sensing imaging for satellite image segmentation 2016 International Journal of Pharmacy and Technology 83.

[39] Sivaraman, K., Senthil, M. Intuitive driver proxy control using artificial intelligence 2016 International Journal of Pharmacy and Technology 84

[40] Sivaraman, K., Kaliyamurthie, K.P. Cloud computing in mobile technology 2016 Journal of Chemical and Pharmaceutical Sciences 92.

[41] Sivaraman, K., Khanna, V. Implementation of an extension for browser to detect vulnerable elements on web pages and avoid click jacking 2016 Journal of Chemical and Pharmaceutical Sciences 9 2 .

\section{AUTHORS PROFILE}

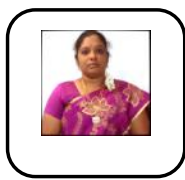

Assistant Professor, Department of Computer Science \& Engineering, Bharath Institute of Higher Education and Research, Chennai, India

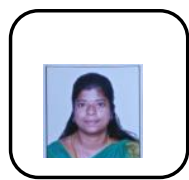

Assistant Professor, Department of Computer Science \& Engineering, Bharath Institute of Higher Education and Research, Chennai, India

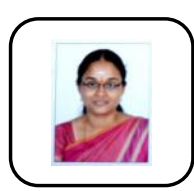

Assistant Professor, Department of Computer Science \& Engineering, Bharath Institute of Higher Education and Research, Chennai, India 